\title{
El acceso a la justicia concebido como derecho humano imperativo (ius cogens)
}

\author{
Joaquín R. Argés \\ Doctor en Derecho por la Universidad de Santiago de Compostela, Galicia. España. \\ joarges@hotmail.com
}

Recibido: 18/12/2017

Dictaminado: 20/02/2018

\section{Resumen}

En el presente artículo aborda el tópico del acceso a la justicia concebido como un derecho humano de carácter imperativo (ius cogens). El trabajo comienza con una reseña sobre el significado del derecho de acceso a la justicia, su origen, concepción actual y su consagración como derecho humano. A continuación, se efectúa un breve apunte sobre el ius cogens y se analizan las consecuencias derivadas de considerar al derecho de acceso a la justicia como parte del ius cogens (su superioridad jerárquica y la generación de obligaciones erga omnes). Antes de finalizar, se resume brevemente el fallo del TEDH para el asunto Al-Dulimi and Montana Management Inc. c/ Suiza, en el que en un ober dictum la mayoría del tribunal señala que per se el acceso a la justicia no tiene carácter ius cogens. Para concluir, se efectúan algunas consideraciones finales.

Palabras clave: Acceso a la justicia, derechos humanos, derechos imperativos, ius cogens.

\section{Access to Justice Understood as a Peremptory Human Right (jus cogens)}

\begin{abstract}
This article deals with the topic of access to justice conceived as a human right with peremptory nature (jus cogens). The work begins with a review of the meaning of access to justice right, its origin, current conception and its consecration as a human right. Then, a brief note is made about the topic of jus cogens and the consequences derived from
\end{abstract}


considering access to justice right as part of it (its hierarchical superiority and the generation of erga omnes obligations). Before concluding, we briefly summarize the ECtHR's decision for the case of Al-Dulimi and Montana Management Inc. v Switzerland, in which, in an ober dictum, the majority of the Court notes that, per se, access to justice right does not have peremptory character. To conclude, some final considerations are made.

Key words: Access to justice, human rights, peremptory norms, jus cogens.

\section{Sumario}

I. Introducción; II. El significado de la expresión «acceso a la justicia». 2.1 Origen del derecho de acceso a la justicia. 2.2 Sentido actual de la expresión y su consagración en los instrumentos de DDHH; III. Apunte sobre los derechos imperativos (ius cogens); IV. El acceso a la justicia concebido como un derecho humano de carácter imperativo (ius cogens); V. Fallo del TEDH en el asunto Al-Dulimi and Montana Management Inc. c/ Suiza; VI. Consideraciones; Bibliografía.

\section{Introducción}

El presente artículo aborda el acceso a la justicia concebido como un derecho humano. Se sostiene que este derecho fundamental en la actualidad forma parte del ius cogens actual. La teoría que defiende la existencia de ciertos derechos de carácter imperativo en el derecho internacional todavía se encuentra en construcción, aunque su origen pueda remontarse al derecho romano. La idea del ius cogens puede constituir una herramienta muy útil para la consagración de la existencia de una jerarquía normativa en el ámbito internacional, tradicionalmente considerado como un conjunto de relaciones meramente horizontales entre los Estados. Una vez que una norma o principio adquiere el carácter de ius cogens, vincula a toda la comunidad internacional, obligando a los Estados a adecuar sus legislaciones y prácticas jurídicas.

Por otro lado, es innegable la relación entre el acceso a la justicia con la protección práctica de los derechos humanos, ya que de este acceso a la justicia depende la vigencia real de estos derechos esenciales. La jurisprudencia de los 
tribunales nacionales e internacionales durante los últimos años si bien ha ido robusteciendo el contenido del derecho de acceso a la justicia no se ha pronunciado todavía de manera contundente al respecto.

Esperamos que este breve artículo pueda aportar —al menos- un granito de arena en la importante misión de la doctrina de promover al desarrollo teórico y práctico en favor de una mayor protección de los derechos fundamentales.

\section{El significado de la expresión «acceso a la justicia»}

La expresión «acceso a la justicia» se compone de dos partes: la que hace referencia a la voz acceso y la que se refiere al vocablo justicia. La Real Academia Española de la lengua (RAE) ${ }^{1}$ señala que en sus primeras tres acepciones la voz acceso (del latín accessus) significa: «1. acción de llegar o acercarse; 2. entrada o paso; 3. entrada al trato o comunicación con alguien».

Por su parte, en cuanto al vocablo justicia (del latín iustitia) nadie discute que tiene una multiplicidad de significados. Entre las acepciones que nos interesan la RAE menciona que justicia significa: «1. principio moral que lleva a dar a cada uno lo que le corresponde o pertenece; 2. derecho, razón, equidad; 3 . conjunto de todas las virtudes por el que es bueno quien las tiene; 4 . aquello que debe hacerse según derecho o razón; 5. pena o castigo público; 6. Poder judicial».

Las primeras acepciones que nos acerca esta definición son las clásicas del derecho romano atribuidas a UlPIANO, y se encuentran recogidas en las Institutas y en el Digesto, y textualmente dicen: «la justicia es la constante y perpetua voluntad de dar a cada uno lo suyo $»^{2}$, «vivir honestamente, no dañar a otros y dar a cada uno lo suyo $»^{3} \mathrm{y}$ «ius se deriva de iustitia, que significa el arte de lo bueno y lo equitativo» $»^{4}$.

\footnotetext{
1 Diccionario de la lengua española de la Real Academia Española, Edición del Tricentenario, RAE, 23ª ed., Madrid, 2014.

2 Institutas 1.1 (Ulpianus de iustitia et iure) «Iustitia est constans et perpetua voluntas ius suum cuique tribuens». Véase Corpus iuris civilis, versión digital alojada en el sitio web The Roman New Library, fundada por Alexander Koptev e Yves Lassard <http://droitromain.upmf-grenoble.fr> (Acceso: 12/11/2017).

3 Institutas 1.1.3 (Ulpianus de iustitia et iure) «Iuris praecepta sunt haec: honeste vivere, alterum non laedere, suum cuique tribuere».

4 Digesto 1.1.1 (Ulpianus libro primo institutionum. pr.) «Iuri operam daturum prius nosse oportet, unde nomen
} 
La tercera acepción concibe a la justicia como virtud. ARISTÓTELES, que se dedica al tópico de la justicia en el libro V de su Ética a Nicómaco ${ }^{5}$ (Aristóteles: 1970, pag. 77 - 80), la define como «la disposición en virtud de la cual los hombres practican lo que es justo, obran justamente y quieren lo justo» ${ }^{6}$ (Aristóteles: 1970, pag. 1129a), Para él, la justicia es la práctica de la virtud perfecta, y considera que es perfecta porque el que la posee puede usar de esta virtud para con otro, y no solo en si mismo. Esta clase de justicia no es para él una parte de la virtud, sino la virtud entera; y por otro lado, la injusticia — su contraria - no es parte del vicio, sino el vicio total ${ }^{7}$ (Aristóteles: 1970, pag. 1129 b y 1130a).

ArISTÓTELEs también explica que junto con la justicia virtud total existe lo que puede denominarse justicia parcial. Esta justicia parcial, explica, está formada por la justicia distributiva y la justicia conmutativa (o correctiva). La justicia distributiva es aquella que es conforme a la proporción, es decir, distinguiendo entre distintos; y la justicia conmutativa, la que tiene que ver con la igualdad de trato, siendo los jueces los encargados de castigar a quien se ha aprovechado en el conflicto en perjuicio de la víctima ${ }^{8}$ (Aristóteles: 1970, pag. 1131a y 1132a). Esta última, se estaría refiriendo a la justicia como pena o castigo público.

En cuanto a la aplicación de la justicia, ArIstóteles cree que ir al juez es ir a la justicia, como su encarnación, como término medio, y por ese motivo sostiene que en algunas partes a los jueces se los llama mediadores, en el sentido de que se alcanzará la justicia si por medio de ellos se llega a lo intermedio. Para el Estagirita el encargado de restablecer la igualdad es, por lo tanto, el juez, «como si de una línea cortada en partes desiguales, quitara a la mayor el trozo en que excede a la mitad y lo añadiera al segmento menor ${ }^{9}$ (Aristóteles: 1970, pag. 1132a). De estas enseñanzas de Aristóteles resulta que la justicia puede entenderse como una virtud parcial (justicia distributiva y conmutativa), y

iuris descendat. Est autem a iustitia appellatum: nam, ut eleganter Celsus definit, ius est ars boni et aequi».

5 Véase Aristóteles, Ética a Nicómaco, edición bilingüe y traducción por M. Araujo y J. Marías, introducción y notas de J. Marías, Instituto de Estudios Políticos, reimp. $1^{\mathrm{a}}$ ed., Madrid, 1970, pp. 70-88.

6 Véase Aristóteles, Ética a Nicómaco, libro V, Cap. 1, 1129 a.

7 Véase Aristóteles, Ética a Nicómaco, libro V, Cap. 1, 1129 b y 1130 a.

8 Véase ArIstóteles, Ética a Nicómaco, libro V, Cap. 3, 1131 a y 1132 a.

9 Véase Aristóteles, Ética a Nicómaco, libro V, Cap. 4, 1132 a. 
también como la virtud total.

La cuarta acepción de la RAE se refiere a la justicia como valor jurídico. Francisco Puy y Milagros Otero Parga — profesores de Filosofía del Derecho en la Universidad de Santiago de Compostela— definen al valor jurídico justicia como:

«la realidad espiritual, que deviene accidente material en la persona que interviene en un acontecimiento de conflicto sobre bienes, sin salirse de la trayectoria que conduce a la plenitud de su existencia individual» ${ }^{10}$ (Otero: 2012, pag. 227).

En opinión de estos destacados catedráticos hay algunos valores que son especialmente relevantes en toda experiencia jurídica a los que califican de valores jurídicos cardinales, que constituyen el eje del plexo circular de los valores presentes en todos los fenómenos de la experiencia jurídica. Entre estos valores, consideran que la justicia es el valor supremo y primero en jerarquía. En otro grupo de valores de carácter superior sitúan a la libertad, la igualdad y el pluralismo. Finalmente, y como valores principales, mencionan a la dignidad, la legalidad y la $\mathrm{paz}^{11}$ (Otero: 2012 pag. 209 y 210).

Veamos ahora la última acepción, que es la que se refiere al Poder Judicial, a la justicia institución. En este sentido, la voz justicia significa el conjunto de órganos personales e instrumentos materiales mediante los cuales se cumple la función social de decir y ejecutar los derechos controvertidos ${ }^{12}$ (Otero: 2012, pag. 225 y 226).

De lo mencionado hasta aquí resulta que la expresión acceso a la justicia quiere decir entonces: el acercamiento, entrada o comunicación con la justicia, esta última con sus diferentes significados (como institución, como virtud total y parcial, como derecho, como principio y como valor jurídico).

\footnotetext{
10 Otero Parga, M. y Puy Muñoz, F., Jurisprudencia dialéctica, Editorial Tecnos, Madrid, 2012, §12.8, p. 227. 11 Véase Otero Parga, M. y Puy Muñoz, F., Jurisprudencia dialéctica, Editorial Tecnos, Madrid, 2012, §11.2728 , pp. 209 y 210.

12 Véase Otero Parga, M. y Puy Muñoz, F., Jurisprudencia dialéctica, Editorial Tecnos, Madrid, 2012, §12.3, pp. 225 y 226.
} 


\subsection{Origen del derecho de acceso a la justicia}

Los autores coinciden en situar el origen del derecho de acceso a la justicia (en el sentido de acceso a la jurisdicción) durante la época posterior a las revoluciones norteamericana (1776) y francesa (1789). Se encargan, sin embargo, de aclarar que este derecho era una cuestión puramente formal, ya que el Estado no tenía todavía como cometido — ni estaba entre sus deberes - que todas las personas pudieran valerse del derecho y de sus instituciones. Recién con el reconocimiento pleno de los derechos de las personas se consolidó la idea de que ese acceso a la jurisdicción debía ser real y no sólo teórico, siendo obligación del Estado que posee el monopolio de la fuerza - solucionar los conflictos que se susciten entre las personas de acuerdo con sus respectivos ordenamientos jurídicos ${ }^{13}$ (Marabotto: 2013, pag. 292 y 293).

El derecho de igualdad ante la ley surgido en las revoluciones de fines del siglo XVIII se hizo efectivo, por lo tanto, con el reconocimiento de los derechos sociales, esto es, aquellos que requieren un actuar positivo del Estado ${ }^{14}$ (Bobbio; 1991, pag. 18 y 19).

\subsection{El sentido actual de la expresión y su consagración en los instrumentos de DDHH}

En la actualidad el derecho de acceso a la justicia tiene un sentido mucho más amplio que el de mero acceso a la jurisdicción, esto refuerza la idea de que la voz justicia debe entenderse en un sentido amplio que incluya todos los aspectos del término. Por lo tanto, este acceso, paso o comunicación debe garantizarse no sólo a la justicia institución (Poder Judicial), sino también a la justicia concebida como principio, virtud, derecho y como valor jurídico.

Se convierte, por lo tanto, en una obligación de los Estados garantizar

13 Véase Marabotto Lugaro, J. A., «Un derecho humano esencial: el acceso a la justicia», Anuario de Derecho Constitucional Latinoamericano Edición 2003, Konrad-Adenauer-Stiftung, $9^{\mathrm{a}}$ ed., Montevideo, 2003, pp. 292 у 293.

14 Véase Boвbio, Norberto, El tiempo de los derechos, traducción de Rafael de Asís Roig, Editorial Sistema, Madrid, 1991, pp. 18 y 19. 
que todos los ciudadanos, sin importar su nacionalidad, raza, sexo, ideología, religión, o nivel económico, puedan acceder a las instancias judiciales para defender o reclamar sus derechos, y que ese acceso se desenvuelva en un proceso justo en el sentido más amplio de esta palabra: sin costes y costas prohibitivos, sin demoras, con un juez imparcial, con las garantías del debido proceso, y que concluya con una aplicación razonada y equitativa del derecho. Es éste el sentido que, en nuestra opinión, ha alcanzado en la actualidad este derecho.

En el ámbito internacional el derecho humano de acceso a la justicia se encuentra recogido principalmente en los arts. 8 y 10 de la Declaración Universal de Derechos del Hombre (DUDH) ${ }^{15}$ de 1948; y en los arts. 2 y 14 del Pacto Internacional de Derechos Civiles y Políticos (PIDCP) ${ }^{16}$, que entró en vigor en marzo de 1976.

En el sistema interamericano de DDHH el derecho de acceso a la justicia está consagrado principalmente en los arts. 8 y 25 de la Convención Americana de Derechos Humanos (CADH) también denominada Pacto de San José de Costa Rica, que entró en vigor en julio de $1978^{17}$. Por su parte, en el ámbito europeo, el derecho de acceso a la justicia se encuentra consagrado en el denominado Convenio Europeo de Derechos Humanos (CEDH) de 1950, que en su art. 6 habla de las garantías del debido proceso y en el art. 13 que se refiere al derecho a un recurso efectivo ${ }^{18}$. Por último, y también en el ámbito comunitario europeo, debemos mencionar el art. 47 de la Carta de los Derechos Fundamentales de la Unión Europea (CDFUE) de $2007^{19}$.

De todos estos artículos resulta sin lugar a dudas que el derecho de acceso a la justicia está consagrado de manera positiva como un derecho humano.

15 Doc. A/RES/217(III) Declaración Universal de Derechos del Hombre (10 de diciembre de 1948).

16 Doc. A/RES/2200(XXI) Pacto Internacional de Derechos Civiles y Políticos (16 de diciembre de 1966).

17 Convención Americana sobre Derechos Humanos, hecha en San José de Costa Rica el 22 de noviembre de 1969.

18 Convenio para la protección de los Derechos y de las Libertades Fundamentales, hecho en Roma el 4 de noviembre de 1950.

19 Carta de los Derechos Fundamentales de la Unión Europea, hecho en Estrasburgo el 12 de diciembre de 2007. 


\section{Apunte sobre los derechos imperativos (ius cogens)}

Como ya lo hemos señalado, sostenemos que el derecho de acceso a la justicia — además de ser un derecho humano - ha adquirido en la actualidad carácter de ius cogens. Pero, ¿qué es el ius cogens? ¿qué son los derechos imperativos? A continuación realizamos un breve apunte sobre su significado.

La expresión latina ius cogens ya aparece en varios pasajes del Digesto justinianeo $^{20}$. Sin embargo, no habría tenido entonces el sentido que se le atribuye en la actualidad, como resulta de las traducciones de D'Ors y GARCíA DEL CORRAL ${ }^{21}$. A pesar de ello, tal y como lo mencionan varios autores ${ }^{22}$, la idea del ius cogens habría estado igualmente presente en la concepción romana del ius publicum, al establecerse que los acuerdos entre los particulares no podían alterar o derogar el derecho público ${ }^{23}$.

En segundo lugar, debemos mencionar que la figura del ius cogens está íntimamente relacionada con el nacimiento y desarrollo del derecho internacional. La aparición de las primeras nociones sobre el derecho internacional — como lo entendemos hoy - surgieron durante el siglo de oro español, fundamentalmente por obra de los destacados miembros de la denominada Escuela de Salamanca, y en especial gracias al genio de Francisco de Vitoria, que fue el primero en concebir al derecho de gentes como un derecho del totus orbis ${ }^{24}$ (Vitoria: 1967,

20 Los siguientes pasajes del Digesto contienen la expresión: Dig. 50.17.82, Dig. 39.5.29, Dig. 13.7.42 y Dig. 7.8.12.6.

21 La expresión iure cogere del Digesto fue traducida por estos maestros como equivalente a las siguientes frases: conforme a derecho, obligado por el derecho, forzado por el derecho, con derecho puede obligar, etc. Véase D’Ors, A., El Digesto de Justiniano. Versión castellana por A. D’Ors, F. Hernández-Tejero, P. Fuenteseca, M. García-Garrido y J. Burillo, Editorial Aranzadi, tomos 1 y 3, Pamplona, 1968 y 1975; Véase García del Corral, I. L., Cuerpo del derecho civil romano: a doble texto, traducido al castellano del latino, con las variantes de las principales ediciones antiguas y modernas y con notas referencias, Publicado por los hermanos Kriegel, Hermann y Osenbrüggen, Jaime Molinas Editor, tomos 1 y 3, Barcelona, 1889 y 1897.

22 Entre ellos: Gómez Robledo y Erik Suy. Véase Gómez Robledo, A., El ius cogens internacional: Estudio histórico-crítico, Universidad Autónoma de México, $1^{a}$ reimp., México, 2003, pp. 12 y 13.); Véase Suy, E., «The Concept of jus cogens in Public International Law», Papers and proceedings II, The Concept of jus cogens in International Law, Conference on International Law (Lagonissi, Greece, April 3-8, 1966), Carnegie Endowment for International Peace, Geneva, 1967, pp. 18 y 19.

23 El Digesto recoge este principio en los siguientes pasajes: Dig. 2.14.38 y Dig. 50.17.45.

24 Véase Vitoria, F. de, Relectio de indis o Libertad de los indios, Edición crítica bilingüe por L. Pereña y 
pag. 80). Años más tarde, Hugo Grocio — otro destacado precursor del derecho internacional — publicó de forma anónima su conocidísima obra Mare Liberum ${ }^{25}$ (Grocio: 1956, pag. 12 y 13) en la que puso sobre la mesa la discusión sobre la posibilidad de la apropiación del mar. A partir de entonces, destacados juristas de todas las latitudes comenzaron a hablar de la libertad de los mares, que junto con la prohibición de la piratería y la prohibición de la esclavitud, habrían sido los primeros ejemplos de normas internacionales de carácter imperativo ${ }^{26}$ (Baptista: 1997, pag. 255 - 265). Podemos señalar que desde esa época hasta nuestros días se han ido incorporando a esta lista de principios y normas imperativas, otras prohibiciones y obligaciones (la prohibición de la trata de personas, la prohibición de la tortura, los principios del derecho humanitario, etc.).

Otro importante antecedente de la existencia de normas imperativas es de mediados de siglo XVIII con la conocida clasificación del derecho en necesario y voluntario defendida por Christian WoLfF $^{27}$ (Wolff: 1934, pag. 10 y 11) y Emmer de VATTEL ${ }^{28}$ (Vattel: 1916, pag. 3 - 5), y años más tar de, por el jur ista suizo Johann BLunTSCHLI ${ }^{29}$ (B1 unt schl i: 1881, pag. 62) y el ital iano Pasquale FIORE $^{30}$ (Fiore: 1885, pag. 150 - 152), siendo el der echo necesario aquel que no admite dispensa, y el voluntario aquel de carácter mudable.

A principios del siglo XIX, con la sanción en 1804 del Código Civil Francés en su art. 6 se positiviza el principio romano sobre la primacía del orden

J. M. Pérez Prendes, Corpus Hispanorum de Pace, Consejo Superior de Investigaciones Científicas, Madrid, 1967, p. 80.

25 Véase Grocio, H., De la libertad de los mares (Mare liberum), estudio preliminar y versión española por L. García Arias, Instituto de Estudios Políticos, Madrid, 1956.

26 Véase BAPtista, E. C., Ius cogens em direito internacional, Lex, Lisboa, 1997, pp. 255-265.

27 Véase WolfF, C., Jus gentium methodo scientifica pertractatum, translation by J. H. Drake, Classics of International Law, Carnegie Endowment for International Peace, Clarendon Press, Vol. II, London, 1934, Prolegomena, § 4 y 5, pp. 10 y 11.

28 Véase VATTEL, E. de, Le droit des gens ou principes de la loi naturelle, appliques a la conduite \& aux affaires des nations \& des souverains (The Law of Nations or the Principles of Natural Law), translation by C. G. Fenwick, Carnegie Institution of Washington, Vol. III, Washington, 1916, Introduction (Preliminaires), § 1-9, pp. 3-5.

29 Bluntschli clasifica al derecho internacional en convencional y necesario. Véase Bluntschli, J., Droit international codifie, traduit de l'Allemand par M. C. Lardy, $3^{\mathrm{a}}$ éd. revue et très augmentée, Libraire Guillaumin et Cie., Paris, 1881, § 13, pp. 62.

30 Véase Fiore, P., Nouveau droit international public, traduite de l'Italien et anotée par C. Antoine, A. Durant et Pedone-Lauriel Éditeurs, t. 1, Paris, 1885, § 157 y 158, pp. 150-152. 
público y las buenas costumbres, que no pueden ser derogadas por convenciones particulares. Se habría producido aquí la introducción de la noción de ius cogens en el derecho positivo del orden interno de los Estados ${ }^{31}$.

Años más tarde se produce otro hito que provocará la generalización de la utilización de la expresión ius cogens. Se trata de la obra de los pandectistas alemanes Cristian von GLÜCK ${ }^{32}$ y Bernhard WINDSCHEID ${ }^{33}$ que fueron los encargados de retomar la clasificación romana del derecho en cuanto a sus efectos en la dicotomía ius dispositivum - ius cogens (imperativo). Habría sido WiNDSCHEID el responsable de elaborar la primera definición del ius cogens con las características descriptivas con las que lo entendemos en la actualidad ${ }^{34}$.

Entre mediados de siglo XIX y principios del XX las discusiones sobre el ius cogens toman un nuevo rumbo y comienzan a girar sobre el debate del contenido de los tratados. Numerosos autores durante este período señalan que los tratados cuyo objeto sea ilícito, moralmente imposible o contradiga a las buenas costumbres, son nulos ${ }^{35}$. Éste sería el principal argumento utilizado —un

31 El Código Civil español refleja también esta idea en sus arts. 1255 y 6.3, al igual que el resto de códigos que siguen esta tradición jurídica romana continental. Así el art. 1255 dice: «Los contratantes pueden establecer los pactos, cláusulas y condiciones que tengan por conveniente, siempre que no sean contrarios a las leyes, a la moral ni al orden público»; y el art. 6 dice « [... 3. Los actos contrarios a las normas imperativas y a las prohibitivas son nulos de pleno derecho, salvo que en ellas se establezca un efecto distinto para el caso de contravención». Código Civil, Real Decreto de 24 de julio de 1889, Ministerio de Gracia y Justicia (España), BOE $n^{\circ} 206$, de 25 de julio de 1889, Referencia: BOE-A-1889-4763.

32 GLÜCK habla de Permissivrecht y Zwangsrecht (ius cogens). Véase GLücK, C., Handbuch zum systematischen Studium des neuesten römischen Privatrechts nach den Grundsätzen des H. Ober Appell. Raths von Günther, Johann Jacob Palm, Erlangen, 1812, p. 133.

33 Véase WindscheID, B., Lehrbuch des Pandektenrechts, Verlagshandlung von Julius Buddeus, t. 1, Düsseldorf, 1862 , p. 65.

34 Su definición es la siguiente: «§30. Ius cogens y derecho permisivo. Existen normas legales que excluyen cualquier arbitrio privado; se utilizan, quieran o no las partes, de manera forzada. Otras normas toleran que la relación pertinente sea ordenada por arbitrio privado y sólo se aplican cuando no está presente una regulación del arbitrio privado». La traducción es nuestra. En el texto original en alemán puede leerse: «§30. Zwingendes und nachgiebigesrecht. Es gibt Rechtssätze, welche jede Privatwillkühr ausschließen; sie kommen zur Anwendung, mögen die Parteien wollen oder nicht, sie zwingen. Andere lassen es sich gefallen, daß das betreffende Verhältnis; durch Privatwillkühr anders geordnet werde, und kommen nur dann zur Anwendung, wenn eine Ordnung des Verhältnisses durch Privatwillkühr nicht vorliegt» [sic]. WINDSCHEID, B., Lehrbuch des Pandektenrechts, Verlagshandlung von Julius Buddeus, t. 1, Düsseldorf, 1862, p. 65.

35 Entre los autores que hablan sobre la necesidad de licitud del objeto de los tratados podemos mencionar entre muchos otros a: August Wilhelm Heffter (Véase Heffter, A. G., Le droit international public de l'Europe, 
siglo más tarde - por el destacado internacionalista austríaco Alfred VERDROsS para sentar las bases de la existencia de un ius cogens internacional ${ }^{36}$.

Una vez finalizada la Segunda Guerra Mundial y con la creación de la Organización de las Naciones Unidas, luego de varios años de trabajo, la Comisión de Derecho Internacional (CDI) propone un proyecto que culminará con la aprobación de la Convención de Viena sobre el Derecho de los Tratados (1969) por la que se positiviza el ius cogens en el ámbito del derecho de los $\operatorname{tratados}^{37}$. Esta idea que consagra la existencia de normas imperativas se fue extendiendo gradualmente a partir de entonces al resto del ordenamiento jurídico internacional, aunque todavía con algunas voces críticas ${ }^{38}$.

Ya en el siglo XXI, y a pesar de la ausencia de un catálogo de normas

traduit sur la III édition de l'original Allemand et augmenté par Jules Bergson, Schroeder, Berlín 1857, § 83, pp. 174-176.); Alphonse Rivier (Véase Rivier, A., Principes du droit des gens, Éditeur Arthur Rousseau, t. 2, Paris, 1896, p. 57-62.); Leopoldo de Neumann (Véase Neumann, L. de, Derecho internacional publico moderno, traducción, prólogo y notas por Aniceto Sela, La España Moderna, Madrid, 1900, § 25 y 26, pp. 110-114); Jan de Louter (Véase Louter, J. de, Le droit international public positif, Oxford: Imprimerie de l'Université, Humphrey Milford, t. 1, London, 1920, pp. 474-492); Lassa Oppenheim (Véase Oppenheim, L., International Law: a Treatise, Edited by Ronald F. Roxburgh, Longmans, Green and Co., $3^{\mathrm{a}}$ ed., t. 1 (Peace), London, 1920, pp. 661 y 662); Paul Fauchille (Véase Fauchille, P., Traité de droit international public, Arthur Rousseau, t. 1, III Partie Paix, $8^{a}$ éd., Paris, 1926, § 819, p. 300); Scipione Gemma (Véase Gemma, S., Appunti di diritto internazionale - Diritto pubblico, Nicola Zanichelli Editore, Bologna, 1923, pp. 208-210).

36 Véase Verdross, A., «Forbidden Treaties in International Law; Comments on Professor Garner's Report on: The Law of Treaties», The American Journal of International law, The American Society of International Law, vol. 31, n 4, Washington, 1937, pp. 571-577; Véase Verdross, A., "Trattati contra bonos mores», Rivista di Diritto Internazionale, Athenaeum, vol. XVI, Roma, 1937, pp. 3-11; Véase Verdross, A., «Jus dispositivum and jus cogens in international law», The American Journal of International Law, The American Society of International Law, Vol. 60, $\mathrm{n}^{\circ}$ 1, Washington, 1966, pp. 53-63.

37 Convención sobre el derecho de los Tratados, redactada en Viena el 23 de mayo de 1969. Entró en vigor el 27 de enero de 1980. Naciones Unidas, Recueil des Traités, versión oficial en español, vol. 1155, 1-18232, 1980, pp. 443-466.

38 Entre los críticos se encuentra el jurista y profesor polaco Jerzy SzTucki, para quien la mentada unanimidad en cuanto a la aceptación de la idea de un ius cogens internacional carece de fundamento. Véase Sztucki, J., Jus cogens and the Vienna Convention on the Law of Treaties: A Critical Appraisal, Springer-Verlag, Österreichische Zeitschrift für öffentliches Recht - Supplementum 3, Wien \& New York, 1974, pp. 54-56. Otro destacado crítico del ius cogens fue el jurista alemán Georg SchwarzenBerger que destaca que la propia Comisión de Der echo Internacional admitió que no ha existido todavía un criterio general que permita identificar reglas generales de derecho internacional con carácter de ius cogens. Véase SchWARZENBERGER, G., «Int er nat ional jus cogens?», in Papers and Proceedings II, The Concept of jus cogens in International Law, Conference on International Law (Lagonissi, Greece, April 3-8, 1966), Carnegie Endowment for International Peace, Genève, 1967, p. 119. 
ius cogens - parafraseando a la profesora QuisPe REMÓN ${ }^{39}$-, algunos autores ensayaron en los últimos años enumeraciones de estos principios, normas y prohibiciones fundamentales considerados de carácter imperativo ${ }^{40}$.

En nuestra opinión, las consecuencias de considerar a un principio o a una norma como perteneciente al ius cogens son principalmente dos: su superioridad jerárquica sobre las demás normas y la generación de obligaciones erga omnes.

En 1995 el profesor español José Acosta EstÉvez escr ibió un trabajo sobre esta relación existente entre las normas de ius cogens, y el efecto erga omnes, para determinar las zonas de influencia de estas figuras. Utilizó para ello los conceptos de jerarquía y de eficacia normativa. Para Acosta Estévez la relación entre disposiciones de ius cogens y las normas dispositivas debe resolverse, en primer lugar, de acuerdo al principio de jerarquía normativa, por el cual toda norma dispositiva pactada que esté en oposición con una norma imperativa será nula por infracción del referido principio de ius cogens ${ }^{41}$.

En cuanto a la cuestión de la eficacia, Acosta Estévez habla de los efectos erga omnes, es decir, las obligaciones de los Estados con la comunidad internacional. En su opinión, la eficacia de las normas de ius cogens siempre es erga omnes. Sin embargo, sostiene que no toda norma con efecto erga omnes forma parte del ius cogens, ya que existirían también otras normas que si bien tienen eficacia respecto a toda la comunidad internacional poseen carácter de ius dispositivum y pueden ser dejadas de lado por acuerdo entre las partes ${ }^{42}$.

39 Véase Quispe Remón, F., «Las normas de ius cogens: ausencia de catálogo», Anuario Español de Derecho Internacional - 2012 Vol. 28, Universidad de Navarra, Pamplona, 2012, pp. 143-183.

40 Entre estas enumeraciones debe destacarse la contenida en la obra colectiva dirigida por RAMIRo BRETóns y las desarrolladas en décadas anteriores por los profesores Carrillo Salcedo y Marín López. Véase Remiro Bretóns, A.; Riquelme Cortado, R.; Orihuela Calatayud, E.; Díez-Hochleitner, J. \& Pérez-Prat Durbán, L., Derecho internacional: Curso general, Tirant Lo Blanch, Madrid, 2010, pp. 234-236; Véase CARrillo SAlcedo, J. A., Soberanía del estado y derecho internacional, Editorial Tecnos, $2^{\mathrm{a}}$ ed., Madrid, 1976, pp. 279-285; Véase MaRín López, A., «Las normas imperativas en derecho internacional», en Estudios de derecho internacional público y privado: Homenaje al profesor Luis Sela Sampil, Secretariado de Publicaciones, Universidad de Oviedo, Oviedo, 1970, pp. 77-80.

41 Véase Acosta Estévez, J. B., «Nor mas de ius cogens, efecto erga omnes, crimen internacional y la teoría de los círculos concéntricos», Anuario Español de Derecho Internacional - 1995 Vol. XI, Revista del Departamento de Derecho Internacional Público, Facultad de Derecho, Universidad de Navarra, Pamplona, 1995, pp. 3-22. 42 Véase Acosta Estévez, J. B., «Nor mas de ius cogens, efecto erga omnes, crimen internacional y la teoría de los círculos concéntricos», Anuario Español de Derecho Internacional - 1995 Vol. XI, Revista del Departamento 
Esta concepción amplia del ius cogens — más allá del ámbito del derecho de los tratados - parece estar aquí para quedarse. Prueba de ello es que — además de las decisiones de la Corte Internacional de Justicia, la Corte Interamericana de DDHH y el Tribunal Europeo de $\mathrm{DDHH}^{43}$ - la Comisión de Derecho Internacional ha incluido en su agenda el tópico del ius cogens como uno de los temas a tratar durante el próximo lustro.

\section{En marzo de 2016 el jurista sudafricano Dire D. TLADI — relator especial de la CDI a estos efectos - emitió su primer informe en el que propuso la siguiente caracterización del ius cogens:}

«1. Se entiende por normas imperativas de derecho internacional (ius cogens) las normas de derecho internacional general aceptadas y reconocidas por la comunidad internacional de Estados en su conjunto, que no admiten modificación, suspensión o abrogación.

2. Las normas de ius cogens amparan los valores fundamentales de la comunidad internacional, son jerárquicamente superiores a otras normas de derecho internacional, y son de aplicación universal» ${ }^{44}$.

de Derecho Internacional Público, Facultad de Derecho, Universidad de Navarra, Pamplona, 1995, pp. 15-22. En este mismo sentido se expresa el profesor CARRILlo SALCEDo, para quien las obligaciones que se derivan de una norma o de un principio de naturaleza imperativa o de ius cogens, son obligaciones erga omnes. El profesor también considera que no todas las obligaciones erga omnes proceden de normas imperativas, ya que pueden tener su fuente en otras normas y principios de derecho internacional general. Véase CARRILLO-SALCEDO, J. A., «Droit international et souveraineté des états: Cours général de droit international public», Recueil des Cours - 1996, Académie de Droit International, Martinus Nijhoff, t. 257, The Hague/Boston/London, 1997, pp. 144-146.

43 Entre la jurisprudencia de la CIJ podemos mencionar: «Reservations to the Convention on Genocide», Advisory Opinion: I.C.J. Reports 1951; «Barcelona Traction, Light and Power Company, Limited», Judgment, I.C.J. Reports 1970; «Military and Paramilitary Activities in and against Nicaragua» (Nicaragua v. United States of America). Merits, Judgment. I.C.J. Reports 1986; «Application of the Convention on the Prevention and Punishment of the Crime of Genocide (Croatia v. Serbia)», Judgment, I.C.J, 3 February 2015. Por su parte, en la jurisprudencia de la Corte IDH se destacan los siguientes fallos: «Condición jurídica y derechos de los migrantes indocumentados», Opinión Consultiva OC-18/03 de 17 de septiembre de 2003, Serie A No. 18; «Caso Maritza Urrutia Vs. Guatemala», Fondo, Reparaciones y Costas, Sentencia de 27 de noviembre de 2003, Serie C No. 103; «Caso La Cantuta Vs. Perú», Fondo, Reparaciones y Costas, Sentencia de 29 de noviembre de 2006.

44 Doc. A/CN.4/693: Primer informe sobre el jus cogens. Preparado por Dire Tladi, Relator Especial, Comisión de Derecho Internacional, $68^{\circ}$ período de sesiones: Ginebra, 2 de mayo a 10 de junio y 4 de julio a 12 de agosto de 2016, Naciones Unidas, 2016, §74, p. 50. <http://legal.un.org/docs/?symbol=A/CN.4/693> (Acceso: 


\section{EI acceso a la justicia concebido como un derecho humano de carácter imperativo (ius cogens).}

El derecho humano e imperativo de acceso a la justicia no es - como dijimos - un derecho más, ya que se erige como la garantía más importante de todos los demás derechos humanos, que no serían más que papel mojado si su cumplimiento no se pudiera exigir judicialmente. Esto quiere decir que la vigencia y la efectividad de los derechos, y en especial de aquellos considerados más importantes o fundamentales, depende entonces de que se garantice la entrada o paso libre de obstáculos hacia el sistema judicial y que esa comunicación siga por cauces justos hasta el dictado de una sentencia que debe ser a la vez útil y oportuna, en definitiva, que se haga justicia. En este sentido, el destacado iusfilósofo italiano Norberto BoBвIo señaló que el reconocimiento y efectividad de los derechos humanos además de tener carácter histórico, constituye uno de los principales indicadores del progreso histórico ${ }^{45}$.

En apoyo a nuestra posición en cuanto al carácter imperativo del derecho de acceso a la justicia podemos citar al profesor CARrillo SAlCEDo (1976), que en su enumeración de normas de ius cogens incluyó específicamente a las reglas procesales que garantizan la puesta en práctica derechos fundamentales de la persona humana que todo Estado debe respetar y proteger ${ }^{46}$.

En la actualidad, otro destacado defensor de esta concepción es el jurista brasileño Antonio CANÇADO TRINDADE, expresidente de la Corte Interamericana de Derechos Humanos (Corte IDH) y actual Magistrado de la Corte Internacional de Justicia (CIJ). En su opinión, sin el derecho de acceso a la justicia concebido como contenido material del ius cogens, simplemente no existe el estado de

\footnotetext{
10/11/2017).
}

45 Véase Boвbio, Norberto, El tiempo de los derechos, traducción de Rafael de Asís Roig, Editorial Sistema, Madrid, 1991, pp. 14, 17 y 18.

46 Véase Carrillo Salcedo, J. A., Soberanía del estado y derecho internacional, Editorial Tecnos, $2^{\mathrm{a}}$ ed., Madrid, 1976, pp. 279-285. En este mismo sentido, el profesor Antonio MARíN LóPEZ que asigna carácter imperativo (ius cogens) a la regla que protege los derechos del hombre que todo Estado tiene obligación de garantizar en declaraciones y mediante procedimientos efectivos. Véase MARín López, A., A., «Las normas imperativas en derecho internacional», en Estudios de derecho internacional público y privado: Homenaje al profesor Luis Sela Sampil, Secretariado de Publicaciones, Universidad de Oviedo, Oviedo, 1970, pp. 77-80. 
derecho ${ }^{47}$. El acceso a la justicia es entendido por CANÇADo TRINDADE como la plena realización de la misma, incluyendo la intangibilidad de todas las garantías judiciales, ya que - en su opinión - no cabe duda que las garantías fundamentales, comunes al derecho internacional de los derechos humanos y al derecho internacional humanitario, tienen una vocación universal, y que deben aplicarse en todas y cualesquier circunstancias, ya que «conforman un derecho imperativo, y acarrean obligaciones erga omnes $\rangle^{48}$.

\section{Fallo del TEDH en el asunto Al-Dulimi and Montana Management Inc. c/ Suiza}

El 21 de junio de 2016 el Tribunal Europeo de DDHH dictó su fallo en el asunto Al-Dulimi and Montana Management Inc. c/Suiza. En un ober dictum el Tribunal de Estrasburgo se refirió al derecho de acceso a la justicia y a su relación con el ius cogens ${ }^{49}$.

Los hechos que motivaron el caso comenzaron con una serie de resoluciones del Consejo de Seguridad de las Naciones Unidas, en las que se solicitaba a los Estados embargar los bienes y recursos económicos localizados fuera de Iraq que hubieran pertenecido o estuvieran vinculados con el régimen iraquí de Hussein. En agosto de 1990, siguiendo esta recomendación, Suiza (miembro de la ONU desde 2002) embargó algunas propiedades de Al-Dulimi y la empresa Montana Management Inc, de la que éste era. Depuesto el régimen de Hussern, el titutar del Consejo de Seguridad de las Naciones Unidas adoptó la Resolución No 1483 (2003), por la que ordenaba a la comunidad internacional la confiscación de

47 Corte IDH, «Caso La Cantuta Vs. Perú», Voto Razonado del Juez A. A. Cançado Trindade, Sentencia de 29 de noviembre de 2006, Serie C No. 162, §53, p. 17.

48 Corte IDH, «Caso de la Masacre de Puebl o Bello Vs. Colombia», Voto Razonado del Juez A. A. Cançado Trindade, Sentencia de 31 de enero de 2006, Serie C No. 140, §64, p. 24. El Magistrado reiteró esta opinión en el caso de las Masacres de Ituango Vs. Colombia (2006). CORTE IDH, «Caso de las Masacres de It uango Vs. Colombia», Voto Razonado del Juez A. A. Cançado Trindade, Sentencia de 1 de julio de 2006, Serie C No. $148, \S 47$, p. 17.

49 TEDH, «Al-Dulimi and Montana Management Inc. v. Switzerland», Application $N^{\circ}$ 5809/08, Judgment, Strasbourg, 21 June 2016. 
todos los bienes vinculados al antiguo régimen iraquí. Siguiendo esta resolución, en 2006 el gobierno Suizo confiscó los bienes embargados a AL-Dulimi.

En su sentencia, el TEDH sostuvo que a pesar de que la resolución del Consejo de Seguridad era de obligado cumplimiento, los Estados no podían eximirse de garantizar el derecho de acceso a la justicia. De esta forma, consideró que Suiza no había tomado las medidas necesarias para ello, y que por lo tanto, había violado el artículo 6.1 del $\mathrm{CEDH}^{50}$. Acompañando esta decisión el juez portugués Paulo PINTO de AlbuQuerque en su opinión concurrente manifestó que el art. 6.1 del CEDH es vulnerado cuando se demuestra que no existen alternativas adecuadas de acceso a la justicia para la protección los derechos protegidos por instrumentos internacionales de derechos humanos ${ }^{51}$.

A pesar de que en esta sentencia el Tribunal de Estrasburgo defiende el derecho de acceso a la justicia consagrado por el instrumento de derechos humanos europeo, en su ober dictum estableció textualmente que:

«ni las garantías procesales ni el derecho a un recurso efectivo contenidos en los arts. 6 y 13 CEDH y ni el art. 14 del PIDCP tienen per se carácter de normas imperativas de derecho internacional (ius cogens)»> ${ }^{52}$.

\section{Conclusiones}

Como punto de partida de estas consideraciones finales, proponemos la siguiente definición del derecho de acceso a la justicia:

«es el derecho humano imperativo (ius cogens) que otorga la facultad jurídica de entrada o comunicación con la justicia en sentido amplio, es decir, sin costes y costas prohibitivos, sin demoras, con un juez imparcial, con las garantías del debido proceso, y que concluya con una aplicación razonada y equitativa del derecho».

50 La decisión fue tomada por 15 votos contra 2.

51 TEDH, «Al-Dulimi and Montana Management Inc. v. Switzerland», Application N ${ }^{\circ}$ 5809/08, Concurring Opinion of Judge Pinto de Albuquerque, joined by Judges Hajiyev, Pejchal and Dedov, Strasbourg, 21 June $2016, \S 70$.

52 TEDH, «Al-Dulimi and Montana Management Inc. v. Switzerland», Application No 5809/08, Judgment, Strasbourg, 21 June 2016, §8.4. 
Su carácter de derecho humano - como ya mencionamos - no se discute en la actualidad, y buena prueba de ello puede ser su extensa consagración positiva en los instrumentos internacionales de DDHH que hemos mencionado.

En cuanto a su carácter imperativo (ius cogens) del derecho de acceso a la justicia, en cambio, vimos todavía no hay unanimidad. A pesar de que el TEDH se mostró vacilante en reconocerle este carácter en su fallo para el caso $\mathrm{Al}$ Dulimi, en el sistema interamericano de protección de los derechos humanos sí se le ha reconocido de manera expresa ese carácter. Hemos mencionado también que destacados autores también se han pronunciado en este sentido ${ }^{53}$. El hecho de que el derecho de acceso a la justicia sea considerado como ius cogens, significa que existen obligaciones erga omnes que vinculan a todos los Estados frente a la comunidad internacional, que consisten en garantizar el acceso a la justicia.

Por otro lado, de la definición propuesta de derecho de acceso a la justicia también se desprende que el sentido que debe darse a la voz justicia, no debe ser únicamente el de acceso a la institución judicial, a los tribunales, ya que la justicia del acceso debe estar presente en todos sus aspectos. Así, por ejemplo, la insuficiencia de recursos no puede constituir un impedimento u obstáculo. Por lo tanto, los sistemas de asistencia jurídica gratuita se erigen como garantes fundamentales de este derecho, en especial en épocas de crisis económicas como las que vivimos, en las que sin la existencia de estas garantías grandes colectivos humanos se encontrarían excluidos de acceder a las instituciones y a los procesos judiciales.

Para concluir, volvemos a subrayar la importancia de que la doctrina dedique tiempo al estudio teórico-práctico sobre el derecho de acceso a la justicia y que se logre extender la idea de que el derecho de acceso a la justicia, no es solo un derecho humano, sino que el mismo forma parte del ius cogens, y ocupa un rol decisivo para alcanzar el restablecimiento del Derecho y de la Justicia.

53 Entre ellos nos hemos referido al juez de la CIJ Antonio CANÇADo TRINDADE, al internacionalista Juan Antonio Carrillo Salcedo y al profesor Antonio Marín López, que incl uyen al der echo de acceso a la just icia en sus listas de normas de ius cogens. 


\section{Bibliografía}

Acosta Estévez, José B., «Normas de ius cogens, efecto erga omnes, crimen internacional y la teoría de los círculos concéntricos», Anuario Español de Derecho Internacional - 1995 Vol. XI, Revista del Departamento de Derecho Internacional Público, Facultad de Derecho, Universidad de Navarra, Pamplona, 1995, pp. 3-22.

Aristóteles, Ética a Nicómaco, edición bilingüe y traducción por M. Araujo y J. Marías, introducción y notas de J. Marías, Instituto de Estudios Políticos, reimp. $1^{\mathrm{a}}$ ed., Madrid, 1970.

BAPTISTA, Eduardo Correia, Ius cogens em direito internacional, Lex, Lisboa, 1997.

Bobbio, Norberto, El tiempo de los derechos, traducción de Rafael de Asís Roig, Editorial Sistema, Madrid, 1991.

Carrillo-Salcedo, Juan Antonio, «Droit international et souveraineté des états: Cours général de droit international public», Recueil des Cours - 1996, Académie de Droit International, Martinus Nijhoff, t. 257, The Hague/Boston/London, 1997, pp. 35-221.

Carrillo Salcedo, Juan Antonio, Soberanía del Estado y Derecho Internacional, Editorial Tecnos, $2^{\mathrm{a}}$ ed., Madrid, 1976.

Corpus iuris civilis, versión digital alojada en el sitio web The Roman

New Library, fundada por Alexander Koptev e Yves Lassard <http:// droitromain.upmf-grenoble.fr> (Acceso: 12/11/2017).

D’Ors, Álvaro, El Digesto de Justiniano. Versión castellana por A. D’Ors, F. Hernández-Tejero, P. Fuenteseca, M. García-Garrido y J. Burillo, Editorial Aranzadi, tomos 1 y 3, Pamplona, 1968 y 1975.

García del Corral, Ildefonso L., Cuerpo del derecho civil romano: a doble texto, traducido al castellano del latino, con las variantes de las principales ediciones antiguas y modernas y con notas referencias, Publicado por los hermanos Kriegel, Hermann y Osenbrüggen, Jaime Molinas Editor, tomos 1 y 3, Barcelona, 1889 y 1897.

GLÜCK, Christian Friedrich, Handbuch zum systematischen Studium des 
neuesten römischen Privatrechts nach den Grundsätzen des H. Ober Appell. Raths von Günther, Johann Jacob Palm, Erlangen, 1812. Gómez Robledo, Ant onio, El ius cogens internacional: Estudio históricocrítico, Universidad Autónoma de México, 1ª reimp., México, 2003. Grocio, Hugo, De la libertad de los mares (Mare liberum), estudio preliminar y versión española por L. García Arias, Instituto de Estudios Políticos, Madrid, 1956.

Marabotto Lugaro, Jorge A., «Un derecho humano esencial: el acceso a la justicia», Anuario de Derecho Constitucional Latinoamericano Edición 2003, Konrad-Adenauer-Stiftung, 9a ed., Montevideo, 2003, pp. 291-301.

MARín LóPEZ, Antonio, «Las normas imperativas en Derecho Internacional», en Estudios de Derecho Internacional Público y Privado: Homenaje al profesor Luis Sela Sampil, Secretariado de Publicaciones, Universidad de Oviedo, Oviedo, 1970, 61-80.

Otero Parga, Milagros y Puy Muñoz, Francisco, Jurisprudencia dialéctica, Editorial Tecnos, Madrid, 2012.

Quispe Remón, Florabel, «Las normas de ius cogens: ausencia de catálogo», Anuario Español de Derecho Internacional - 2012 Vol. 28, Universidad de Navarra, Pamplona, 2012, pp. 143-183.

Remiro Bretóns, Antonio; Riquelme Cortado, Rosa; Orihuela Calatayud, Esperanza; Díez-Hochleitner, Javier \& Pérez-Prat Durbán, Luis, Derecho internacional: Curso general, Tirant Lo Blanch, Madrid, 2010.

Schwarzenberger, Georg, «Int er nat ional jus cogens?», in Papers and Proceedings II, The Concept of jus cogens in International Law, Conference on International Law (Lagonissi, Greece, April 3-8, 1966), Carnegie Endowment for International Peace, Genève, 1967, pp. 115-140.

Sztucki, Jerzy, Jus cogens and the Vienna Convention on the Law of Treaties: A Critical Appraisal, Springer-Verlag, Österreichische Zeitschrift für öffentliches Recht - Supplementum 3, Wien \& New York, 1974 
SuY, Erik, «The Concept of jus cogens in Public International Law», Papers and proceedings II, The Concept of jus cogens in International Law, Conference on International Law (Lagonissi, Greece, April 3-8, 1966), Carnegie Endowment for International Peace, Geneva, 1967). VatTel, Emmer de, Le droit des gens ou principes de la loi naturelle, appliques a la conduite \& aux affaires des nations \& des souverains (The Law of Nations or the Principles of Natural Law), translation by C. G. Fenwick, Carnegie Institution of Washington, Vol. III, Washington, 1916.

Verdross, A., «Jus dispositivum and jus cogens in international law», The American Journal of International Law, The American Society of International Law, Vol. 60, $\mathrm{n}^{\mathrm{o}}$ 1, Washington, 1966, pp. 53-63.

Verdross, Alfred, «Forbidden Treaties in International Law; Comments on Professor Garner's Report on: The Law of Treaties», The American Journal of International law, The American Society of International Law, vol. 31, n 4, Washington, 1937, pp. 571-577.

Verdross, Alfred, «Trattati contra bonos mores», Rivista di Diritto Internazionale, Athenaeum, vol. XVI, Roma, 1937, pp. 3-11.

WindsCHEID, Bernhard, Lehrbuch des Pandektenrechts, Verlagshandlung von Julius Buddeus, t. 1, Düsseldorf, 1862.

WolfF, Christ ian (Christ iano Wolfio), Jus gentium methodo scientifica pertractatum, translation by J. H. DRAKE, Classics of International Law, Carnegie Endowment for International Peace, Clarendon Press, Vol. II, London, 1934. 